\title{
TESTIMONIO. EL «AMERICANISMO» DE LOS AÑOS 40 EN ESPAÑA
}

\author{
POR \\ JOSÉ ALCINA FRANCH \\ Universidad Complutense. Madrid.
}

Rememorar los años cuarenta al cabo de medio siglo, para un "americanista" como yo, implica un compromiso en el que se entreveran nostalgia y rabia contenida al mismo tiempo. Esos recuerdos me llevan a aquellos años, "cuando todos éramos jóvenes", pero también cuando la dictadura era más dura e intransigente y cuando la pobreza llegaba hasta el engomado de los sobres o a la blancura y calidad del papel en el que escribíamos nuestros primeros ensayos. Había sobrevenido una catástrofe sobre el país y aún no nos dábamos cuenta cabal de lo que habíamos perdido, aunque algunos lo sabíamos desde hacía años y otros lo empezaban a intuir. Se nos habían ido personas tan importantes como Millares Carlo, Malagón, Bosch Gimpera, Comas, Armillas y también Silvio Zavala o Ángel Rosenblat y tantos otros que no pudieron ser nuestros maestros, pero que serían nuestros amigos muy poco después, unidos por un exilio mutuo. En España nadie hablaba de ellos y tampoco de la brillante floración americanista en plena nefanda II República Española, con la celebración del XXVI Congreso Internacional de Americanistas de Sevilla (1935), con Marañón de presidente y Torroja de secretario general, o con la Cátedra Conde de Cartagena en la autónoma Facultad de Letras de Madrid, por donde ya habían pasado Walter Lehmann, Hermann Trimborn y Fernando Márquez Miranda y a donde hubiese venido el año 36 Eric S. Thompson.

No se hasta qué punto puede ser útil lamentarse retrospectivamente de las cosas que no fueron, que no pudieron ser y pensar cómo hubiesen sido si no hubiese sucedido lo que sucedió. Lo he pensado muchas veces para otros asuntos, quizás más vitales y 
también vale para ésto. La historia del pensamiento en historia o en antropología quedó truncada en aquél momento: el desierto intelectual que dejaron aquéllos intelectuales ¿cómo podríamos sustituirlo?; es cierto que, de algún modo, se sustituyó, pero yo diría que mal. Esa es la rabia contenida que no aminora la nostalgia de los años de nuestra juventud.

Por añadidura, una vez que terminó la guerra civil empezó aquella espantosa II Guerra Mundial, de la que apenas sabíamos nada porque toda la información venía filtrada por las agencias alemanas y sólo las emisoras de Londres y las revistas que conseguíamos en algunas embajadas nos decían algo de la verdad. Muchos esperábamos el final de la guerra como una "liberación" que, finalmente, fue imposible. Cuando nos fuimos asomando al exterior, Europa apenas estaba empezando a levantar cabeza: yo salí muy pronto, en 1950, aún eran palpables las huellas de la tragedia en el mero cogollo de París.

Claro que ese tétrico cuadro no impedía el buen humor de los que aún no habíamos cumplido los treinta años y nos empeñábamos en hacer un "americanismo» también «imposible»: los motes y las secretas burlas a nuestros "jefes" nos compensaban de las miserias intelectuales y morales y de los escuálidos salarios como becarios del CSIC, así como de la tenaz persecución bibliográfica por las escasas y esquilmadas bibliotecas de Madrid. Estas "batallitas» que, yo al menos, no cuento nunca, cuando las rememoro ahora, al cabo de esos cincuenta años me hacen ver que, verdaderamante vivíamos en un helado páramo y sólo nos calentábamos -iMilagro en Milán! - con un rayo de sol.

Por aquellos años el "americanismo» español estaba renaciendo en varios lugares a la vez: en Madrid y Sevilla principalmente, pero también en Barcelona y Valencia. Como casi siempre en nuestro país, era el resultado del esfuerzo personal de algunos de los americanistas de "antes de la guerra" que habían quedado en España por alguna razón fácilmente comprensible o por otras más difíciles de entender para el común de la gente. También era comprensible el tipo de "americanismo" o más bien de Historia de América que se esperaba que se hiciese: la exaltación del "espíritu nacional» y del «imperio" por el que se pretendía llegar a Dios, hacían difícil que nadie se pudiera interesar por los indios americanos y sus culturas, o que se pudieran abordar cuestiones de historia social y económica, sobrepasando así el espíritu de la "Hispanidad» y de la pura historia eclesiástica y de la evangelización de las Indias. A pesar de lo cual, alguien, en algún lugar, 
estaba intentando hacer eso, trabajando increíblemente a la contra de las corrientes dominantes del momento. En efecto, por aquellos años se estaba formando un grupo renovador muy importante en la historiografía española, en torno a la figura de Jaime Vicens Vives y, de algún modo, esa "escuela» estaba difundiendo sus postulados por el resto de las universidades españolas; su influencia en el "americanismo» español sería muy esporádica y débil y, desde luego, llegaría varios años después, quizás demasiado tarde.

Ya he dicho que uno de los focos -al principio único- del americanismo de los años 40 era Madrid. En la Universidad había una Cátedra de Historia de América que regentaba desde 1914 Don Antonio Ballesteros-Beretta, la figura de mayor prestigio en aquellos momentos en el campo del "americanismo" que vendría a morir justo al final de la década, en el verano de 1949, cuando en el lapso de muy pocos años había publicado algunas de sus más importantes contribuciones en ese campo: los estudios sobre Juan Bautista Muñoz, su Cristóbal Colón y el Descubrimiento de América (1945), su Génesis del Descubrimiento (1947) y su estudio sobre Juan de la Cosa que dejaba inédito. Es indudable que Antonio Ballesteros está en el nacimiento de la especialidad de "Historia de América» en la Facultad de Filosofía y Letras y del Instituto "Gonzalo Fernández de Oviedo" del Consejo Superior de Investigaciones Científicas. La sección de Historia de América venía a continuar y ampliar la Cátedra Conde de Cartagena y el Instituto a la Sección Hispanoamericana del Centro de Estudios Históricos. Cuando yo llegué al «Fernández de Oviedo», en 1948 aún andaban volando ejemplares de una página de un Atlas de Historia de América del antiguo Centro. El director era Don Antonio, en cuyo despacho nos reuníamos un día a la semana en una "tertulia" donde se empezaba a recibir a algunos visitantes ilustres del extranjero.

Todo el CSIC estaba inevitablemente bañado por el hálito del Opus Dei que se desprendía de la figura del Padre Albareda. Ese espíritu ha sido particularmente importante en el ámbito del americanismo español. Cuando «aterricé» en el Consejo el grupo liderado por Vicente Rodríguez Casado ya se había desgajado para anidar en Sevilla, creándose la Escuela de Estudios Hispanoamericanos, institución privilegiada que contó muy pronto con imprenta propia y en la que se impartían enseñanzas aún antes de que se crease la sección de Historia de América en la Facultad de Letras en el viejo caserón de calle Laraña. 
Manuel Ballesteros-Gaibrois, que se había doctorado en Berlín con Preuss y Lehmann, "antes de la guerra", obtuvo la Cátedra de Historia Universal de la Universidad de Valencia en 1941. Allí se formaría un tercer núcleo americanista, éste muy modesto y desprotegido, en torno al Seminario «Juan Bautista Muñoz». En ese seminario impartí mi primer curso de arqueología americana el año 1947: un curso sobre «Arqueología peruana", bajo la mirada condescendiente y yo creo que cómplice de la estatua de Luis Vives que presidia nuestro "claustro». Junto a la entusiasta figura de Manuel Ballesteros treintañero pululábamos jóvenes recién licenciados que estábamos descubriendo la Antropología a través de las traducciones de Fondo de Cultura Económica, hechas por exiliados españoles y otros que se orientaban por la historia social o institucional del Nuevo Mundo: Manuel Tejado, Leopoldo Piles, Miguel Enguídanos, Bartolomé Escandell, Mario Hernández y yo mismo. Casi todos nosotros fuimos emigrando a Madrid y recalando en el Instituto "Gonzalo Fernández de Oviedo». Algunos fuimos ayudantes en la Universidad - yo, por ejemplo, lo fui de Don Antonio Ballesteros el curso 1948-49- y «becarios» en el Consejo. La suma de aquellos dos míseros sueldos nos permitían sobrevivir aunque con dificultades, cuando ya no éramos becarios y teníamos plaza en el "Cesar Carlos", el Colegio Mayor donde se estaba reinventando el Socialismo, mientras los "maquis» aún andaban por los montes de España.

El «Fernández de Oviedo» era un sitio agradable donde se trabajaba poco y se hablaba mucho, especialmente en la llamada "Sala de revistas». Entre los más "viejos» del lugar recuerdo a Jaime Delgado, Emilio López Oto, Jorge Campos, Claudio Miralles de Imperial y entre los más jóvenes estábamos Miguel Artola, Carlos Seco, Miguel Enguídanos, Juan Pérez de Tudela y yo mismo. Todos, más o menos, formábamos "familias» o "facciones" en torno a D. Ramón Ezquerra, a D. Ciriaco Pérez Bustamante o a D. Manuel Ballesteros, pese a que éste no regresaría a Madrid hasta 1950. Mientras Don Antonio Ballesteros vivió las peleas entre "familias» no se agudizaron: eso fue ya en los años cincuenta.

El inolvidable y entrañable Jorge Campos, nuestro escritor "americanizado" añadía sal y pimienta a los ingredientes, tan heterogéneos, de aquél Instituto. De agosto del 51 son estos versos dedicados a algunos de quienes se pensaba que irían al Congreso de Peruanistas de Lima: 


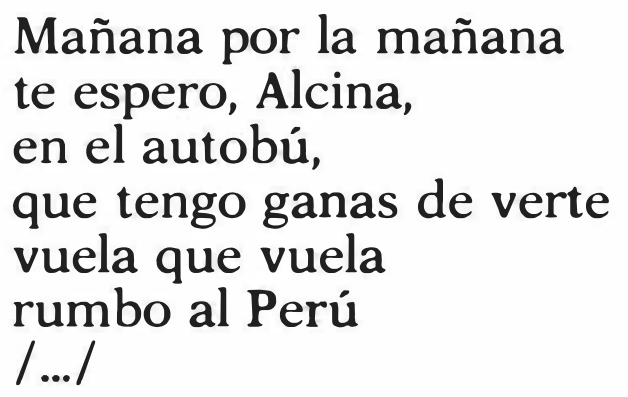

Ezquerra con sus secuaces

y el Artolilla

también se aprestan

para el Perú

llevándose a María Luisa

con su camisa

de canesú

Por aquellos años el Museo de América, en la Universitaria, ya estaba prácticamente terminado, al menos en sus aspectos arquitectónicos más visibles, aunque su inauguración aún tardaría veinte años. Don José Tudela —un «rojo» camuflado a la sombra de Doña Pilar, amiga de Doña Carmen- construía con esfuerzo una biblioteca especializada en la América prehispánica, casi la única en Madrid en aquél tiempo. Y poco más... Porque el Museo Etnológico, por entonces dirigido por un prehistoriador metido a antropólogo físico, único profesional que había excavado recientemente en América - en Colombia - mientras España se hallaba en guerra, Pérez de Barradas, dirigiendo el Instituto Bernardino de Sahagún, se hallaba bastante distanciado del "americanismo", aunque en su revista Antropología y Etnología publiqué un primer y único artículo el año 51.

En agosto de 1947 se reunió en París el XXVIII Congreso Internacional de Americanistas, que era el primero que se celebraba después de la II Guerra Mundial y casi el siguiente al de Sevilla de 1935, ya que en esa trágica década sólo se había celebrado la XXVII sesión en México y Lima en el verano de 1939 - terminada nuestra guerra civil y recién iniciada la mundial-. En esa reunión de París presentaba mis primeras contribuciones, pero no pude asistir; creo recordar que de España solamente estuvieron presentes Luis Pericot, Manuel Ballesteros y José Tudela, pero de algún modo se estaba enlazando con la "tradición" americanista internacional de antes de la guerra.

El americanismo catalán en la década de los 40 casi se reducía 
a la persona de Don Luis Pericot que desde los años 20 venía trabajando en la preparación de las varias versiones de la «América Indigenan: la primera en el libro Lus Razas Humanas del Instituto Gallach (1928) y la segunda en la Historia de América de Antonio Ballesteros, en Salvat (1936). Mi relación personal con Pericot se había iniciado en el Servicio de Investigación Prehistórica de Valencia, donde descubrí la primera biblioteca que me servía para mi inicial especialización en arqueología y de la que dispuse para mis primeros ensayos en ese campo.

El grupo más numeroso, fuerte e influyente en el americanismo español de aquellos años era, sin duda, el grupo sevillano. Alli, la tradición investigadora de ante-guerra se había centrado en el Instituto Hispano-Cubano, con Ots Capdequí, y que después iría languideciendo lentamente, al tiempo que la Escuela de Estudios Hispanoamericanos crecía con impulso gracias al apoyo de Albareda desde Madrid. Los nombres nuevos de Vicente Rodríguez Casado, Florentino Pérez Embid, José Antonio Calderón Quijano, Vicente Palacio Atard, Octavio Gil Munilla o Guillermo Céspedes del Castillo se unían a algunos de la generación anterior o de fuera del "grupo» como Manuel Giménez Fernández, Diego Angulo Iñiguez, Emiliano Jós o Enrique Marco Dorta, con el siempre «independiente» Juan Manzano. Las ediciones iban creciendo: antes de 1950 ya contaban con 54 publicaciones entre las cuales los cinco primeros volúmenes del Anuario de Estudios Americanos. Con el evidente proteccionismo de Madrid se pone de manifiesto en el hecho de que en sólo seis años (1944-49) publicarían 23.000 páginas, cuando el resto del "americanismo" se hallaba prácticamente en la indigencia, lo que, por otra parte, se correspondía a las condiciones generales del país en aquél momento. En efecto, si en Sevilla se publicaban dos revistas: el Anuario y Estudios Americanos, en Madrid sólo se editaba la Revista de Indias y sus publicaciones anejas eran solamente 18 libros editados en toda la década, con un total de 12.000 páginas; es decir, una cuarta parte de lo que se publicaba en Sevilla.

Pero más importante que lo cuantitativo es lo cualitativo. Como ya he dicho en otra ocasión, el desinterés por los temas indígenas ya correspondiesen al período prehispánico como al período colonial y contemporáneo en esa primera década fue casi total: en Sevilla no había nadie que se interesase por el tema; Manuel Ballesteros, que como ya hemos dicho se había doctorado en Berlín la década anterior con un tema sahaguntino, estaba desde 1941 en Valencia enseñando todo lo habido y por 
haber en una Universidad desierta - Historia Universal, Arqueología, Paleografía, etc.- y enseñando a investigar en el Archivo del Reino de Valencia - de esa época es su Valencia y los Reyes Católicos-, y en Madrid sólo estaba Hermann Trimborn, que había pasado varios años investigando y tratando de eludir la tormenta bélica de Europa. Yo estaba empezando a trabajar en ese campo, pero hasta 1949 no publiqué ningún artículo; el primero fue "Nuevas interpretaciones de la figura del shaman en la cerámica Chimún, en el volumen 10 de la Revista de Indias.

Ese "vacío" en los estudios acerca del mundo indígena en el "americanismo» español es significativo. Los "americanistas» españoles siempre han pensado el Nuevo Mundo como un inmenso territorio vacío que había que poblar o como mucho que estaba poblado por "salvajes" a los que había que "civilizar". Nunca se tomó en cuenta - yo creo que ahora mismo tampoco- que la "historia» de ese continente, aun siendo más reciente que la del Viejo Mundo, tenía 40.000 años de antigüedad y que en esos milenios las poblaciones indias habían evolucionado hasta alcanzar el nivel de los Estados antiguos. En mi opinión es esa «carencia" la que ha marcado de una manera decisiva a la interpretación histórica de América desde la perspectiva hispánica; en definitiva no se trata de que la historiografía americanista española sea "anti-indigenista», sino más bien que carece de esa perspectiva $y$, por lo tanto, hace una historia de los españoles o los criollos en América y se olvida del indio en absoluto.

No es mi intención en estas breves páginas hacer ningún juicio de valor, ni ofrecer ninguna visión crítica del americanismo español de los años 40 sino, simplemente, evocar una época que era, por otra parte, la de mi iniciación en este campo, la de mi juventud y la del reinicio de una tradición interrumpida por la guerra civil. 